\title{
IbM Pemantapan Pengelolaan Sistem Pencatatan Keuangan IKM N'Up Product
}

\author{
Yurida Ekawati*, Purnomo, Sunday Noya, Novenda Kartika Putrianto, Teguh Oktiarso, Yuswono \\ Hadi
}

Program Studi Teknik Industri, Universitas Ma Chung, Villa Puncak Tidar N-1 Malang, Indonesia 65151

Correspondence: yurida.ekawati@machung.ac.id

Received: 30 Juni 2021 - Revised: 01 Agustus 2021 - Accepted: 16 Agustus 2021

\begin{abstract}
Abstrak. Perkembangan jumlah UKM di Indonesia semakin pesat. Namun dari sekian banyak UKM, sebagian besar masih mengalami kesulitan yang berhubungan dengan pengelolaan keuangan usaha. Hal ini tidak lepas dari keterbatasan UKM untuk memiliki pengetahuan yang baik tentang pengelolaan dan pencatatan keuangan serta keterbatas akses UKM untuk mendapatkan aplikasi pengelolaan dan pencatatan keuangan sederhana yang sesuai dengan kondisi usaha mereka. Kondisi ini dialami juga oleh N'Up Product, sebuah IKM yang memproduksi produk-produk olahan bawang hitam. Keterbatasan akses dan pengetahuan, mengakibatkan pencatatan keuanganya masih dilakukan secara manual. Membantu mengatasi persoalan ini, Tim Pengabdian Masyarakat Prodi Teknik Industri Universitas Ma Chung, melalui Skim Ma Chung Abdimas Grant (MAG), merancang aplikasi khusus pencatatan keuangan IKM yang berbasiskan Microsoft Excel. Aplikasi ini kemudian diterapkan di IKM N'Up Product sekaligus untuk memperbaiki cara pengelolaan keuangannya. Hasil yang didapatkan melalui program ini, IKM N'Up Product telah memiliki dan menerapkan sebuah sistem pengelolaan dan pencatatan keuangan yang professional, yang pada saatnya nanti akan membantu pengembangan dan peningkatan usahanya.
\end{abstract}

Kata kunci: IKM, Pencatatan Keuangan, Pengabdian pada Masyarakat

Citation Format: Ekawati, Y., Purnomo, Noya, S., Putrianto, N.K., Oktiarso, T., \& Hadi, Y.. (2021). IbM Pemantapan Pengelolaan Sistem Pencatatan Keuangan IKM N'Up Product. Prosiding Seminar Nasional Abdimas Ma Chung (SENAM), 341-348. 


\section{PENDAHULUAN}

Usaha Mikro dan Menengah (UKM) memegang peranan yang sangat penting bagi pembangunan ekonomi nasional Indonesia. Pada tahun 2010 saja, data Badan Pusat Statistik Indonesia menunjukkan jumlah pelaku UMKM merupakan mayoritas yaitu sebesar 99\% dari jumlah perusahaan di Indonesia. UKM juga menyumbang 58\% dari Produk Domestik Bruto (PDB) (Taneo dkk., 2013). Dalam lima tahun terakhir, berdasarkan data Kementerian Koperasi dan Usaha Kecil dan Menengah Republik Indonesia, kontribusi sektor UKM terhadap PDB bahkan meningkat dari 57,84 persen menjadi 60,34 persen (Kementerian Koperasi dan UKM, 2017; Rahman et al., 2017). Selanjutnya penyerapan tenaga kerja di sektor ini mencapai 97 persen. Data tersebut membuktikan potensi UKM sebagai penggerak utama perekonomian bangsa.

Perkembangan jumlah UKM di Indonesia dari tahun ke tahun terlihat semakin pesat. Pada kenyataanya jika dilihat lebih teliti terutama pada aspek pengelolaan usaha, masih terdapat banyak sekali hambatan yang berhubungan dengan pengelolaan keuangan usaha. Hal ini tidak lepas dari keterbatasan UMKM untuk memiliki pengetahuan yang baik tentang pengelolaan dan pencatatan keuangan serta keterbatas akses UMKM untuk mendapatkan aplikasi pengelolaan dan pencatatan keuangan sederhana yang sesuai dengan kondisi usaha mereka.

N’Up Product adalah IKM pemegang Merek Floresko, Zoelkies dan Dzulhi, terletak di Perum Sekarsari Indah B.28, Sumbersekar, Dau, Kab. Malang. Produk utama yang dikeluarkan oleh UMKM N'Up Product ini adalah bawang hitam atau biasa disebut dengan black garlic. Black garlic sendiri berbahan dasar utama bawang putih yang difermentasi secara alami tanpa tambahan bahan apapun dengan suhu panas $60^{\circ} \mathrm{C}-70^{\circ} \mathrm{C}$ pada Magic Com dalam kurun waktu kurang lebih 14 hari. Sehingga bawang putih nantinya akan terurai dan teroksidasi serta berubah warna menjadi hitam dan tekstur bawang putih menjadi lunak serta mengeluarkan rasa manis dan sedikit asam. Bawang hitam ini sangat baik bagi kesehatan.

N'Up Product sendiri telah memiliki legalitas usaha berupa IUMK dengan nomor 503/2153/35.07.22/2018; NPWP nomor 74.233.414.7657100 dan NIB dengan nomor 9120603723802.

Program Pengabdian Masyarakat berbasis Ipteks bagi Masyarakat (IbM) adalah salah satu skim Ma Chung Abdimas Grant (MAG) yang adalah program pemberdayaan 
masyarakat Universitas Ma Chung yang telah dilaksanakan sejak berdirinya Ma Chung pada tahun 2020 .

\section{MASALAH}

Hasil identifikasi didapatkan bahwa salah satu permasalahan yang dihadapi oleh N'Up Product adalah menyangkut proses pencatatan keuangan yang diterapkan masih dilakukan dengan cara manual sederhana pada buku. Sementara itu aplikasi-aplikasi pencatatan keuangan yang khusus dirancang untuk IKM, yang beredar secara umum saat ini, dirasa masih terlalu kompleks dan tidak bisa memenuhi kebutuhan pencatatan keuangan yang sederhana dan mudah dimengerti. Melihat permasalahan ini, Tim Pengabdian Masyarakat Prodi Teknik Industri Universitas Ma Chung merasa perlu untuk memantapkan pengelolaan sistem pencatatan keuangan N'Up Product. Instrumen penyusunan laporan keuangan dan administrasi pada N'Up Product kemudian di rancang oleh Tim Pengabdian Masyarakat bebasis program Microsoft Excel. Pada hakekatnya, kegiatan IbM ini merupakan solusi terhadap permasalahan yang dihadapi IKM melalui pendekatan secara terpadu, agar dapat meningkatkan ketrampilan penyusunan laporan keuangan dan administrasi bebasis komputer.

\section{METODE PELAKSANAAN}

Pada Program Ibm ini dilaksanakan selama bulan Juli dan Agustus 2020 dengan tahapan yang terdapat di Gambar 1. Pelaksanaan program IbM diawali dengan observasi langsung ke tempat produksi N'Up Product di Perum Sekarsari Indah B.28, Sumbersekar, Dau, Kab. Malang. Setelah observasi, kami melakukan diskusi dengan pemilik usaha untuk mengidentifikasikan permasalahan dan kebutuhan usahanya.

Pada program IbM kali ini, kami mengidentifikasi berbagai macam kebutuhan dan permasalahan yang dihadapi dalam menjalankan usaha. Dari sekian banyak permasalahan tersebut, pengelolaan dan pencatatan keuangan merupakan salah satu masalah yang cukup penting untuk segera ditangani. Dari hasil identifikasi ini, dibuatlah perancangan program IbM.

Tahapan selanjutnya adalah perancangan sistem pencatatan keuangan. Sistem atau instrumen ini didesain sesuai kebutuhan dan operasional sehari-hari N'Up Product dengan basis Microsoft Excel. 


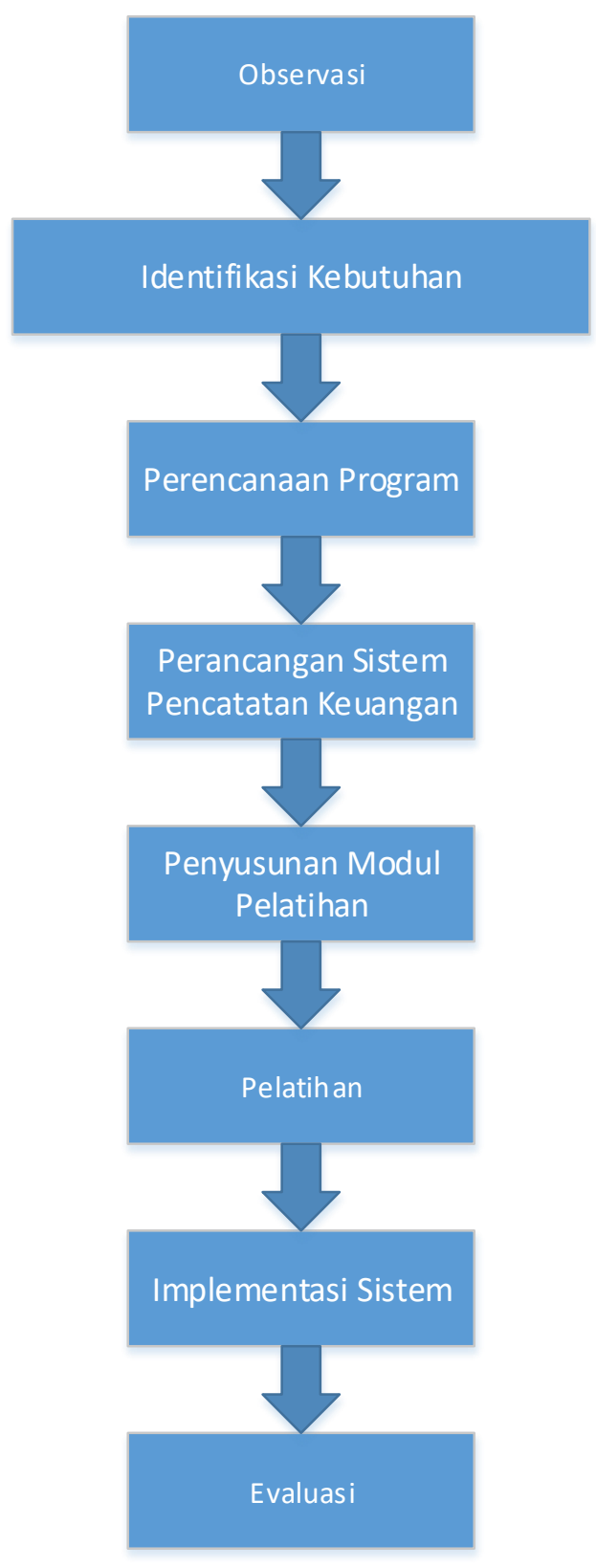

Gambar 1. Diagram Alir Tahapan Pelaksanaan Program IbM

Selanjutnya, agar pemilik dan pegawai IKM terampil mengoperasikan sistem yang dibagun, maka kami melakukan pelatihan penggunaan sistem pencatatan keuangan tersebut. Sebelumnya kami buatkan panduan tertulis, untuk lebih memudahkan pengoperasian sistem. Setelah pelatihan, sistem yang kami rancang diimplementasikan di IKM dengan tetap pelaksanaanya dilakukan dengan pendampingan dari tim. Akhir dari program ini adalah evaluasi terhadap seluruh program. 


\section{HASIL DAN PEMBAHASAN}

Tahapan observasi dan identifikasi masalah kami lakukan dengan datang langsung ke tempat produksi N'Up Product. Observasi dilakukan untuk melihat kondisi IKM dari segala aspek, baik produksi, pengelolaan administrasi, hingga pemasaran produk. Untuk memahami kondisi usaha dengan lebih rinci, kami melakukan diskusi dan wawancara dengan Ibu Neneng Apriana pemilik dan pengelola N'Up Product. Berdasarkan diskusi yang dilakukan, diketahui bahwa pengelolaan dan pencatatan keuangan merupakan salah satu aspek usaha yang selama ini belum dilakukan secara benar. Pembukuan masih dilakukan secara manual, yang berakibat pada kesulitan kalkulasi dan penyimpanan data. Lebih jauh lagi masalah pengelolaan keuangan, yang sering terjadi adalah kesulitan membedakan mata anggaran dan biaya usaha dengan mata anggaran dan biaya rumah tangga. Dokumentasi diskusi dapat dilihat di Gambar 2.

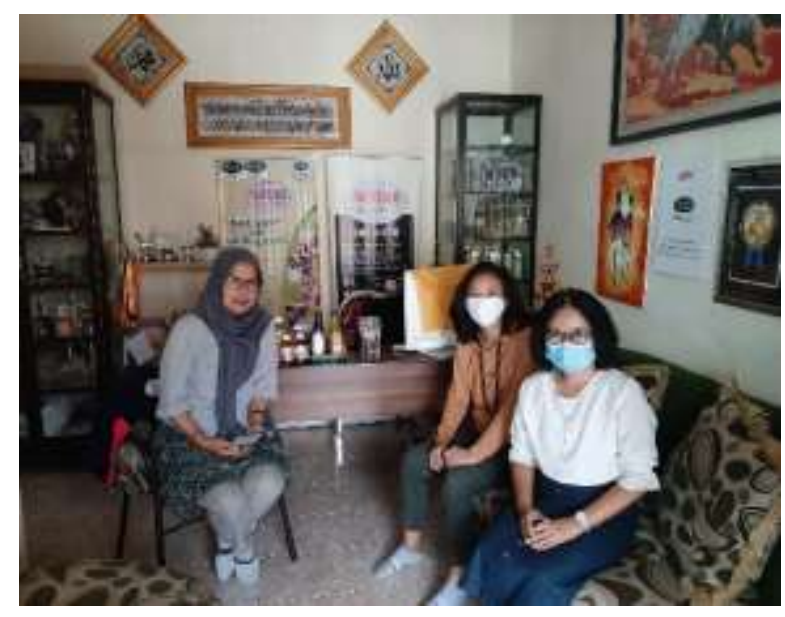

Gambar 2. Diskusi dengan Pemilik N’Up Product

Setelah melakukan perancangan program pengabdian ini secara menyeluruh, langkah berikutnya adalah perancangan sistem pengelolaan dan pencatatan keuangan. Dari hasil diskusi dengan pemilik IKM, diketahui bahwa pencatatan keuangan selama ini masih dilakukan secara manual. Sebenarnya banyak aplikasi-aplikasi pencatatan keuangan yang khusus dibuat untuk standar IKM, dan tersebar secara gratis untuk umum. Salah satu diantaranya yang di rancang dan disebarkan secara gratis oleh Bank Indonesia adalah aplikasi SIAPIK. Namun berdasarkan testimoni dari para pelaku UKM, aplikasi-aplikasi seperti ini masih terlalu kompleks dan sulit dipahami serta dioperasikan pada level usaha mereka. 
Berdasarkan informasi diatas, tim kami merancang sebuah aplikasi pencatat keuangan sederhana berbasiskan Microsoft Excel yang mudah dioperasikan dan disesuaikan mata anggaran dan biayanya dengan kondisi IKM.

Aplikasi pencatatan keuangan ini berupa template Microsoft Excel yang dapat digunakan untuk mencatat keuangan sepanjang tahun. Aplikasi ini dapat digunakan untuk membuat laporan keuangan berupa Beban Pokok Penjualan dan Laporan Laba Rugi. Periode laporan dapat ditentukan oleh pemilik IKM. Untuk input data yang berhubungan dengan penentuan beban pokok penjualan bisa dilakukan setiap tanggal transaksi dilakukan sehingga pemilik tidak perlu membuat jurnal tersendiri untuk semua beban pengeluaran. Demikian juga dengan input untuk pemasukan juga bisa dilakukan untuk setiap transaksi. Untuk memudahkan penggunaan program keuangan ini, biaya per unit di akhir periode menggunakan nilai rata-rata. Beban-beban atas penjualan produk dibuat sesuai kebutuhan IKM tersebut namun dapat diubah sesuai kebutuhan jika kelak dibutuhkan ketika IKM berkembang. Pembuatan laporan untuk periode selanjutnya masih dilakukan secara manual dengan cara membuat salinan laporan periode sebelumnya dan disediakan petunjuk untuk melakukan input data untuk periode yang baru tersebut. Aplikasi ini secara tidak langsung memaksa IKM untuk melakukan pengelolaan keuangannya secara professional, diantaranya dengan memisahkan mata anggaran IKM dengan mata anggaran rumah tangga pemilik IKM. Contoh pencatatan keuangan menggunakan aplikasi yang dirancang dapat dilihat di Gambar 3.

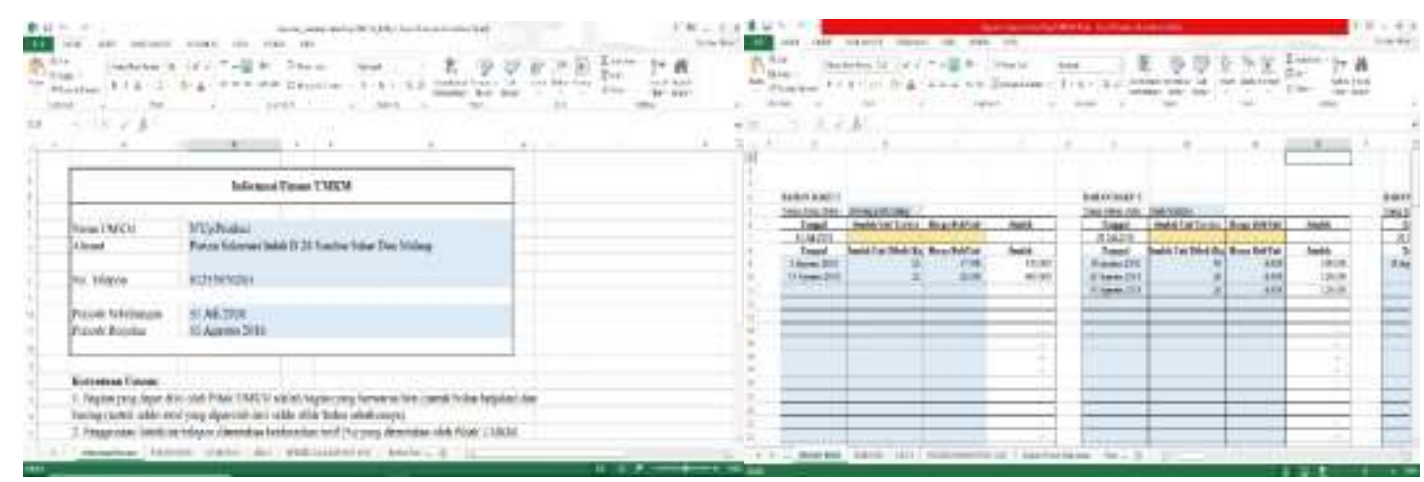

Gambar 3. Contoh Pencatatan Keuangan menggunakan Aplikasi yang dirancang

Setelah aplikasi tersebut siap digunakan, maka tahapan selanjutna adalah melakukan pelatihan pengoperasian aplikasi tersebut kepada staf administrasi N'Up Product. Pelatihan ini dilakukan dalam beberapa tahapan untuk memastikan keterampilan teknis si pengguna. 
Pelatihan ini dilakukan hingga IKM siap untuk menerapkannya dalam usaha. Dokumentasi pelatihan dapat dilihat di Gambar 4.

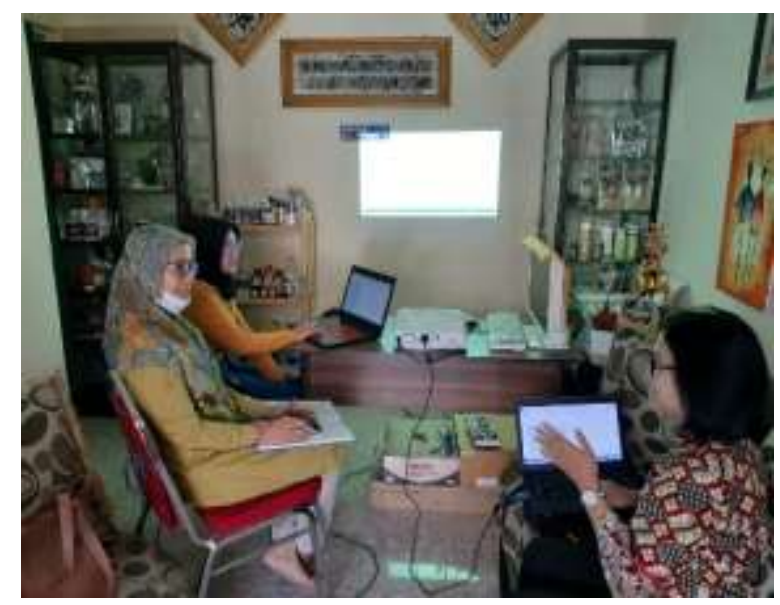

Gambar 4. Pelatihan Penggunaan Aplikasi Pencatatan Keuangan dan Pengelolaan Keuangan

Tahapan terakhir dari program pengabdian pada masyaraka ini adalah implementasi sistem pengelolaan dan pencatatan keuangan IKM yang kami kembangkan di N'Up Product. Selama implememtasi dilakukan, tim kami tetap melakukan pendampingan untuk memastikan bahwa aplikasi digunakan secara benar dan tepat sasaran.

\section{KESIMPULAN}

Pengelolaan dan pencatatan keuangan secara profesional masih menjadi kendala bagi banyak IKM hingga saat ini. Pengetahuan yang minim serta kompleksnya sistem pengelolaan keuangan usaha yang beredar umum saat ini, membuat para pengelola IKM memutuskan untuk melakukan pencatatan keuangan usahanya secara manual. Tim Pengabdian Masyarakat Prodi Teknik Industri Universitas Ma Chung, melalui Skim Ma Chung Abdimas Grant (MAG), dalam upayanya membantu IKM N'Up Product, merancang aplikasi khusus pencatatan keuangan IKM yang berbasiskan Microsoft Excel. Setelah dilaksanakan pelatihan pengoperasian, aplikasi tersebut saat ini telah digunakan oleh IKM N'Up Product dengan sangat baik. Diharapkan, dengan menggunakan aplikasi sederhana ini, pengelolaan keuangan usaha pada IKM N'Up Product akan lebih profesional. Pada akhirnya pengelolaan keuangan yang profesional ini akan berkontribusi positif pada pengembangan dan peningkatan usaha N'Up Product kedepan. 


\section{UCAPAN TERIMA KASIH}

Para penulis mengucapkan terima kasih kepada Universitas Ma Chung yang telah memberi dukungan finansial terhadap kegiatan Pengabdian melalui Skim IPTEKS bagi Masyarakat Ma Chung Abdimas Grant (MAG) 2020.

\section{DAFTAR PUSTAKA}

Kementerian Koperasi dan UKM. (2017).

http://www.depkop.go.id/uploads/laporan/1549946778_UMKM\%2020162017\%20rev.pdf

Rahman, A. A., Hamid, U. Z. A., \& Chin, T. A. (2017). Emerging Technologies with Disruptive Effects/ : A Review. PERINTIS EJournal, 7(2), 111-128

Taneo, S. Y., Stephanus, D. S., \& Setiyati, E. A. (2013). The Innovation Speed and Its Impact on Competitiveness of Small and Medium-Sized Enterprises. 1st Asia Pacific Management and Business Application International Conference on Management and Business Science (pp. 189-207). Batu: FEB UB. 